\title{
Correlation of Neck Circumference With Abdominal Circumference and Body Mass Index in Patients With Metabolic Syndrome in a Hospital From Northern Peru: A Cross-sectional Study
}

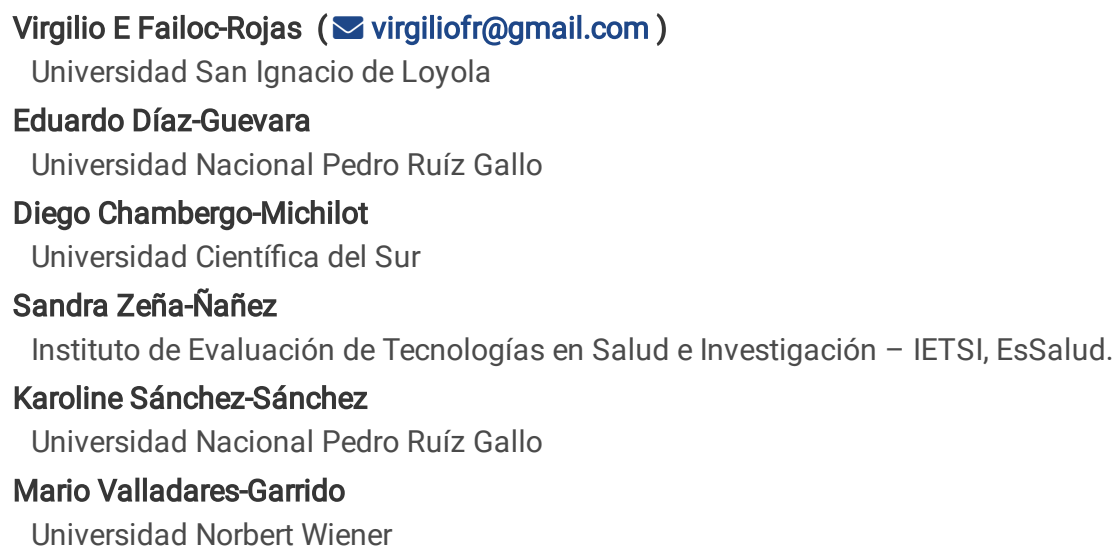

\section{Research Article}

Keywords: internal medicine, neck, body mass index, body weights and measures

Posted Date: November 30th, 2021

DOI: https://doi.org/10.21203/rs.3.rs-980122/v2

License: (c) (i) This work is licensed under a Creative Commons Attribution 4.0 International License. Read Full License 


\section{Abstract}

We aimed to evaluate the correlation of neck circumference with abdominal circumference and body mass index in patients with metabolic syndrome in Chocope, Trujillo. This cross-sectional study included patients with untreated metabolic syndrome. Health professionals measured the anthropometric parameters of participants as per the international guidelines. Pearson's correlation coefficients and single and multiple regression models were used for analysis. Data from 250 participants showed homogeneous distribution with respect to age, comorbidities, and biochemical properties according to sex. The mean age was 53.6 years. A positive correlation of neck circumference with abdominal circumference ( $r=0.6$ and 0.74 for females and males, respectively) and body mass index ( $r=0.51$ and 0.65 for females and males, respectively) was observed. The linear correlation model showed that a 1-cm increase in neck circumference increased the abdominal circumference by 2.20 $\mathrm{cm}(\mathrm{p}<0.001)$ and $2.27 \mathrm{~cm}(\mathrm{p}<0.001)$ and body mass index by $0.72 \mathrm{~kg} / \mathrm{m}^{2}(\mathrm{p}<0.001)$ and $0.94 \mathrm{~kg} / \mathrm{m}^{2}(\mathrm{p}<0.001)$ in males and females, respectively, independent of other variables. In participants with metabolic syndrome in this study, neck circumference showed a strong correlation with abdominal circumference and body mass index. This anthropometric parameter can be extremely useful for evaluating obesity among patients with metabolic syndrome.

\section{Background}

The definition of metabolic syndrome includes clinical criteria for central obesity, dyslipidemia, glycemia, and blood pressure (1). In Latin America, metabolic syndrome has a prevalence of $24.9 \%$, with higher rates observed in women and individuals aged $>50$ years (2). Metabolic syndrome is associated with multiple risk factors, including endocrine disorders, lifestyle habits, and obesity $(3,4)$. Moreover, metabolic syndrome is the most important risk factor for type 2 diabetes mellitus and cardiovascular events (3), both of which are closely related to obesity.

Several anthropometric parameters are used as predictors of metabolic syndrome, including body mass index (BMI), abdominal circumference, neck circumference, waist-hip ratio, waist-height ratio (5), and body shape index (6). Apart from neck circumference, the remaining anthropometric parameters are estimated by measuring more than one body parameter with light clothing, which could possibly introduce measurement errors.

The neck circumference indicates the amount of subcutaneous fat deposit in the cervical area. This parameter has been validated and is a simple method of predicting overweight, obesity (7), cardiovascular risk factors $(7,8)$, and type 2 diabetes mellitus (9). BMI, abdominal circumference, and neck circumference are accurate predictors of metabolic syndrome, type 2 diabetes mellitus, and cardiovascular disease (6, 8, 9). Neck circumference can be measured quickly and effortlessly, with no variations in measurement during the day under normal conditions. Moreover, it strongly correlates with the adiposity indices (10).

These anthropometric parameters can be used to evaluate metabolic syndrome and its complications in a healthy population. However, little is known regarding the correlation among anthropometric measurements in patients with metabolic syndrome considering the potential presence of variations (10). Therefore, the current study aimed to evaluate the correlation of neck circumference with abdominal circumference and BMI in patients with metabolic syndrome from Chocope, Trujillo.

\section{Methods}

\section{Population and sample}

A cross-sectional study using data derived from a secondary clinical database was conducted. The primary study evaluated patients with metabolic syndrome at Chocope Hospital II-1 from January to December 2016. Patients who satisfied the criteria for metabolic syndrome according to the National Cholesterol Education Program's Adult Treatment Panel III (NCEP-ATP III) (1) were included, whereas those with thyroid disease, cirrhosis, abdominal tumors, and other health conditions that interfere with neck and abdominal circumference measurements were excluded.

With the 250 participants enrolled in the primary study, the power of the study was estimated considering an expected correlation coefficient ( $r$ ) of $0.5 \pm 0.1$ between neck circumference and abdominal circumference (11) and a 95\% confidence interval. Accordingly, the study power was estimated to be $98 \%$. The primary study employed a systematic random sampling method to enroll the initial number of estimated patients from the outpatient clinic of the internal medicine department.

\section{Data collection}

The primary study involved conducting interviews with health personnel. The survey, which was designed based on the RENATA-1 survey (12), included measurements of social, demographic, and anthropometric parameters (weight, height, abdominal circumference, and neck circumference) as well as levels of blood pressure, glucose, high-density lipoprotein (HDL), and triglycerides (TG). The RENATA-1 survey uses the 
Latin American Diabetes Association's criteria with the following cutoff points: abdominal obesity of $>94$ and $>88 \mathrm{~cm}$ for men and women, respectively, and neck obesity of $\geq 41$ and $\geq 35 \mathrm{~cm}$ for men and women, respectively.

Blood samples were collected after $8 \mathrm{~h}$ of fasting to measure the levels of TG, glycemia, and HDL. Anthropometric parameters were measured in an upright position with patients in light clothing. Weight, height, abdominal circumference, and blood pressure were measured following the WHO guidelines (12). Weight was measured using a digital scale calibrated with an error of $0.1 \mathrm{~kg}$. Neck circumference was measured using a tape with an accuracy of $1 \mathrm{~mm}$, starting from the lower margin of the laryngeal prominence below the thyroid cartilage, which is perpendicular to the axial axis, with the participant's head following the horizontal Frankfurt's plane (13). Abdominal circumference was measured using a tape with an accuracy of $1 \mathrm{~mm}$, starting from the midpoint between the lowest rib and the iliac crest on the midaxillary line.

\section{Variables}

The outcomes of interest in this study were BMI $\left(\mathrm{kg} / \mathrm{m}^{2}\right)$ and blood pressure $(\mathrm{mmHg})$, with neck circumference (cm) being the main independent variable. All parameters were measured during the same interview by the same interviewer.

\section{Statistical analysis}

Age, BMI, and neck circumference are presented as means and standard deviations, whereas categorical variables are reported as frequencies and percentages. Pearson's correlation coefficients were estimated to determine differences between subgroups of interest. Simple linear regression models using the Gaussian distribution family and the identity link function were employed to evaluate the association of neck circumference with abdominal circumference and BMI. The final multiple linear regression model was adjusted for age, hypertension, hypertriglyceridemia, and hyperglycemia and stratified according to sex; 95\% confidence intervals ( $95 \% \mathrm{Cl})$ were estimated and significant $\mathrm{p}$ values of $<0.05$ were reported. The dataset was initially exported in Microsoft Excel $2010 \AA$ and analyzed using STATA v.14.0 (College Station, TX: StataCorp LLC).

\section{Ethics}

The primary study was approved by the Institutional Review Board of the Hospital II-1 Chocope and the School of Human Medicine from the Universidad Nacional Pedro Ruiz Gallo. Informed consent was obtained. The primary study followed ethical principles by minimizing risks when obtaining blood samples from participants and protecting their physical and mental well-being. Similarly, in our secondary data analysis, study participants were anonymized by removing any personal information that could identify them. All methods were performed in accordance with the relevant guidelines and regulations.

\section{Results}

Among the 250 participants included in this study, 67.6\% were women; $85.2 \%, 46.0 \%$, and $43.6 \%$ had high blood pressure, hyperglycemia, and obesity, respectively. Their average age was 53.6 years, and both males and females had similar BMI. However, there were differences in neck and abdominal circumferences according to sex. Accordingly, men had slightly higher values of mean anthropometric parameter measurements than women. However, women had a higher prevalence of disorders related to blood pressure, abdominal circumference, and neck circumference than men (Table 1). 
Table 1

Characteristics of patients with metabolic syndrome from a hospital in La Libertad-

Peru according to sex

\begin{tabular}{|c|c|c|c|}
\hline & $\begin{array}{l}\text { Females } \\
(n=169)\end{array}$ & $\begin{array}{l}\text { Male } \\
(n=81)\end{array}$ & All \\
\hline & $\mathbf{N}(\%)$ & $\mathbf{N}(\%)$ & $\mathbf{N}(\%)$ \\
\hline Age * & $53.6(10.3)$ & $51.9(11.7)$ & $53(10.8)$ \\
\hline Body mass index * & $29.2(5.0)$ & $29.9(3.9)$ & $29.5(4.7)$ \\
\hline Neck circumference * & $37.1(2.5)$ & $42.5(3.5)$ & $38.9(3.8)$ \\
\hline Abdominal circumference * & $98.8(9.3)$ & $104.9(10.1)$ & $100.8(10.0)$ \\
\hline \multicolumn{4}{|l|}{ Hypertension } \\
\hline Yes & $147(87.0)$ & $66(81.5)$ & $213(85.2 \%)$ \\
\hline No & $22(13.0)$ & $15(18.5)$ & $37(14.8 \%)$ \\
\hline \multicolumn{4}{|l|}{ Hyperglycemia } \\
\hline Yes & $69(40.8)$ & $46(56.8)$ & $115(46 \%)$ \\
\hline No & $100(59.2)$ & $35(43.2)$ & $135(54 \%)$ \\
\hline \multicolumn{4}{|l|}{ Hypertriglyceridemia } \\
\hline Yes & $162(95.9)$ & $73(90.1)$ & $235(94.0 \%)$ \\
\hline No & $7(4.1)$ & $8(9.9)$ & $15(6.0 \%)$ \\
\hline \multicolumn{4}{|c|}{ Increased abdominal circumference } \\
\hline Yes & $164(97.0)$ & $75(92.6)$ & $239(95.6 \%)$ \\
\hline No & $5(3.0)$ & $6(7.4)$ & $11(4.4 \%)$ \\
\hline \multicolumn{4}{|l|}{ Increased neck circumference } \\
\hline Yes & $154(91.1)$ & $63(77.8)$ & $217(86.8 \%)$ \\
\hline No & $15(8.9)$ & $18(22.2)$ & $33(13.2 \%)$ \\
\hline
\end{tabular}

A significant positive correlation of neck circumference with weight (0.6276), abdominal circumference (0.6595), and BMI (0.4477) was noted. Moreover, neck circumference was correlated with abdominal circumference and BMI in both men and women ( $p<0.001)($ Figure 1). However, other variables, such as age, arterial hypertension, hypertriglyceridemia, and hyperglycemia, were not correlated with abdominal circumference or BMI in either sex (Table 2). 
Table 2

Correlation of neck circumference with abdominal circumference in patients with metabolic syndrome by sex

\begin{tabular}{|c|c|c|c|c|c|c|c|c|c|c|c|c|}
\hline \multirow[b]{3}{*}{ Parameters } & \multicolumn{6}{|c|}{ Abdominal circumference } & \multicolumn{6}{|l|}{ BMI } \\
\hline & \multicolumn{3}{|l|}{ Males } & \multicolumn{3}{|c|}{ Females } & \multicolumn{3}{|l|}{ Males } & \multicolumn{3}{|c|}{ Females } \\
\hline & Coef & $95 \% \mathrm{Cl}$ & $p^{*}$ & Coef & $\begin{array}{l}95 \% \\
\mathrm{Cl}\end{array}$ & $p^{*}$ & Coef & $\begin{array}{l}95 \% \\
\mathrm{Cl}\end{array}$ & $p^{*}$ & Coef & $\begin{array}{l}95 \% \\
\mathrm{Cl}\end{array}$ & p* \\
\hline $\begin{array}{l}\text { Neck } \\
\text { circumference }\end{array}$ & 2.18 & $\begin{array}{l}1.74 \text { to } \\
2.62\end{array}$ & $<0.001$ & 2.21 & $\begin{array}{l}1.76 \\
\text { to } \\
2.66\end{array}$ & $<0.001$ & 0.73 & $\begin{array}{l}0.54 \\
\text { to } \\
0.92\end{array}$ & $<0.001$ & 0.91 & $\begin{array}{l}0.68 \\
\text { to } \\
1.15\end{array}$ & $<0.001$ \\
\hline Age & -0.09 & $\begin{array}{l}-0.28 \\
\text { to } 0.11\end{array}$ & 0.378 & 0.07 & $\begin{array}{l}-0.06 \\
\text { to } \\
0.21\end{array}$ & 0.299 & -0.06 & $\begin{array}{l}-0.13 \\
\text { to } \\
0.01\end{array}$ & 0.107 & -0.03 & $\begin{array}{l}-0.09 \\
\text { to } \\
0.04\end{array}$ & 0.465 \\
\hline \multicolumn{13}{|l|}{ Hypertension } \\
\hline No & Ref. & & & Ref. & & & Ref. & & & Ref. & & \\
\hline Yes & -2.98 & $\begin{array}{l}-8.72 \\
\text { to } 2.76\end{array}$ & 0.305 & -0.49 & $\begin{array}{l}-4.24 \\
\text { to } \\
4.14\end{array}$ & 0.981 & -1.22 & $\begin{array}{l}-3.42 \\
\text { to } \\
0.97\end{array}$ & 0.271 & -0.23 & $\begin{array}{l}-2.27 \\
\text { to } \\
1.81\end{array}$ & 0.826 \\
\hline \multicolumn{13}{|l|}{ Hyperglycemia } \\
\hline No & Ref. & & & Ref. & & & Ref. & & & Ref. & & \\
\hline Yes & 1.21 & $\begin{array}{l}-3.32 \\
\text { to } 5.73\end{array}$ & 0.597 & -1.16 & $\begin{array}{l}-4.03 \\
\text { to } \\
1.70\end{array}$ & 0.424 & 0.31 & $\begin{array}{l}-1.42 \\
\text { to } \\
2.04\end{array}$ & 0.724 & -0.30 & $\begin{array}{l}-1.70 \\
\text { to } \\
1.10\end{array}$ & 0.675 \\
\hline \multicolumn{13}{|c|}{ Hypertriglyceridemia } \\
\hline No & Ref. & & & Ref. & & & Ref. & & & Ref. & & \\
\hline Yes & -2.50 & $\begin{array}{l}-10.01 \\
\text { to } 5.01\end{array}$ & 0.509 & -0.38 & $\begin{array}{l}-7.46 \\
\text { to } \\
6.69\end{array}$ & 0.915 & 0.18 & $\begin{array}{l}-2.71 \\
\text { to } \\
3.06\end{array}$ & 0.901 & -0.20 & $\begin{array}{l}-3.64 \\
\text { to } \\
3.25\end{array}$ & 0.911 \\
\hline
\end{tabular}

Multiple linear regression model showed that neck circumference was associated with abdominal circumference and BMI in both sexes, independent of age, high blood pressure, and hyperglycemia. The single and multiple regression models showed that the coefficients of association between neck circumference and abdominal circumference as well as BMI were virtually equal (Table 3). 
Table 3

Multiple linear correlation of neck circumference with abdominal circumference and body mass index in patients with metabolic syndrome by sex

\begin{tabular}{|c|c|c|c|c|c|c|c|c|c|c|c|c|}
\hline \multirow[b]{3}{*}{ Parameters } & \multicolumn{6}{|c|}{ Abdominal circumference } & \multicolumn{6}{|l|}{ BMI } \\
\hline & \multicolumn{3}{|l|}{ Males } & \multicolumn{3}{|c|}{ Females } & \multicolumn{3}{|l|}{ Males } & \multicolumn{3}{|c|}{ Females } \\
\hline & Coef & $\begin{array}{l}95 \% \\
\mathrm{Cl}\end{array}$ & $p^{*}$ & Coef & $95 \% \mathrm{Cl}$ & $\mathrm{p}^{*}$ & Coef & $\begin{array}{l}95 \% \\
\mathrm{Cl}\end{array}$ & p* & Coef & $\begin{array}{l}95 \% \\
\mathrm{Cl}\end{array}$ & p* \\
\hline $\begin{array}{l}\text { Neck } \\
\text { circumference }\end{array}$ & 2.20 & $\begin{array}{l}1.77 \\
\text { to } \\
2.63\end{array}$ & $<0.001$ & 2.27 & $\begin{array}{l}1.82 \text { to } \\
2.72\end{array}$ & $<0.001$ & 0.72 & $\begin{array}{l}0.53 \\
\text { to } \\
0.91\end{array}$ & $<0.001$ & 0.94 & $\begin{array}{l}0.70 \\
\text { to } \\
1.18\end{array}$ & $<0.001$ \\
\hline Age & 0.01 & $\begin{array}{l}-0.12 \\
\text { to } \\
0.12\end{array}$ & 0.995 & 0.06 & $\begin{array}{l}-0.04 \\
\text { to } 0.17\end{array}$ & 0.244 & -0.03 & $\begin{array}{l}-0.09 \\
\text { to } \\
0.02\end{array}$ & 0.267 & -0.03 & $\begin{array}{l}-0.09 \\
\text { to } \\
0.03\end{array}$ & 0.348 \\
\hline \multicolumn{13}{|l|}{ Hypertension } \\
\hline No & Ref. & & & Ref. & & & Ref. & & & Ref. & & \\
\hline Yes & -3.16 & $\begin{array}{l}-7.53 \\
\text { to } \\
1.21\end{array}$ & 0.157 & -1.29 & $\begin{array}{l}-5.14 \\
\text { to } 2.56\end{array}$ & 0.511 & -1.11 & $\begin{array}{l}-3.04 \\
\text { to } \\
0.81\end{array}$ & 0.257 & -0.53 & $\begin{array}{l}-2.56 \\
\text { to } \\
1.50\end{array}$ & 0.607 \\
\hline \multicolumn{13}{|l|}{ Hyperglycemia } \\
\hline No & Ref. & & & Ref. & & & Ref. & & & Ref. & & \\
\hline Yes & 0.61 & $\begin{array}{l}-2.93 \\
\text { to } \\
4.16\end{array}$ & 0.157 & -1.88 & $\begin{array}{l}-4.60 \\
\text { to } 0.83\end{array}$ & 0.175 & 0.25 & $\begin{array}{l}-1.31 \\
\text { to } \\
1.81\end{array}$ & 0.754 & -0.66 & $\begin{array}{l}-2.09 \\
\text { to } \\
0.76\end{array}$ & 0.363 \\
\hline \multicolumn{13}{|c|}{ Hypertriglyceridemia } \\
\hline No & Ref. & & & Ref. & & & Ref. & & & Ref. & & \\
\hline Yes & -3.88 & $\begin{array}{l}-9.29 \\
\text { to } \\
1.53\end{array}$ & 0.160 & -6.18 & $\begin{array}{l}-12.19 \\
\text { to } \\
-0.18\end{array}$ & 0.043 & -0.25 & $\begin{array}{l}-2.63 \\
\text { to } \\
2.12\end{array}$ & 0.834 & -2.45 & $\begin{array}{l}-5.62 \\
\text { to } \\
0.71\end{array}$ & 0.129 \\
\hline
\end{tabular}

A 1-cm increase in neck circumference promoted a 2.20- and 2.27-cm increase in abdominal circumference in males and females, respectively (p $<0.001$ ), after adjusting for age, blood pressure, TG levels, and glycemia. Similarly, a 1-cm increase in neck circumference promoted a 0.72- and 0.94-kg/ $\mathrm{m}^{2}$ increase in BMI in males and females, respectively $(\mathrm{p}<0.001)$, after adjusting for age, blood pressure, TG levels, and glycemia (Table 3).

\section{Discussion}

\section{Main findings}

Considering sex disparities in metabolic risk, the current study examined patients with metabolic syndrome from a hospital in northern Peru to evaluate the association between neck circumference and abdominal circumference. Our findings primarily showed that both parameters had a positive linear correlation in both sexes, although anthropometric measurements were more positive in men than in women.

\section{Correlation of neck circumference with abdominal circumference and BMI}

A positive linear correlation of neck circumference with abdominal circumference and BMI was noted in men and women. This finding is consistent with those of previous studies $(11,14)$. A study in Turkey reported a correlation between neck circumference and waist circumference in adult men and women (Pearson's correlation coefficients, $r=0.593$ and $r=0.667$, respectively). Moreover, the same study showed a correlation between neck circumference and BMI in men and women $(r=0.587$ and $r=0.688$, respectively). In both parameters, statistically significant associations were noted $(p<0.001)(11)$. Another outpatient study in the endocrinology department reported that the waist-neck index correlated with abdominal circumference ( 0.61 and 0.46 for men and women, respectively) and BMI (0.51 and 0.41 for men and women, respectively). Moreover, significant associations were observed in both parameters $(p<0.001)(14)$, albeit lower than those reported in a previous study. Although our study found practically similar correlation coefficients for men and women, men had greater values than women. 
Our study evaluated patients with untreated metabolic syndrome; previous studies did not specify this criterion. This could explain why our study showed higher correlation coefficients because individuals with metabolic syndrome gain weight, BMI, and abdominal circumference over time, which could have resulted in an increased correlation among anthropometric parameters by the time these patients presented with an illness (15).

To the best of our knowledge, no study has yet evaluated patients with untreated metabolic syndrome. However, there is evidence in patients with other metabolic diseases $(16,17)$. For example, a recent study in patients with pre-diabetes reported a positive linear correlation between neck circumference and abdominal circumference (16). Moreover, another study reported a significant correlation between both variables in patients with type 2 diabetes (17). Despite the presence of metabolic disorders, the association between both parameters has been consistently reported.

Neck circumference is an anthropometric parameter that measures the distribution of subcutaneous fat in the upper body, thereby helping predict metabolic risk $(8,18)$. Several studies have supported the association between neck circumference and components of the metabolic syndrome, including abdominal circumference and BMI. A recent systematic review that addressed the association of neck circumference with cardiometabolic markers reported a significant association between neck circumference and abdominal circumference, fasting glycemia, the homeostatic model assessment of insulin resistance, and lipid profile (19).

Previous studies have consistently found that neck circumference is positively correlated with abdominal circumference, BMI, and other cardiovascular markers, such as the lipid risk profile, suggesting that neck circumference is a prognostic factor for mortality in patients with a high cardiovascular risk $(6,8,19)$. Dai et. al. studied adults with two or more risk factors for cardiovascular disease and reported that an increased neck circumference was associated with a higher incidence of cardiovascular events and mortality (8).

Our study found that the correlation of neck circumference with abdominal circumference and BMI was higher in men than in women. The finding, however, is not homogeneous across studies worldwide. Several studies comparing the correlation between neck circumference and abdominal circumference according to sex have demonstrated higher coefficients in women than in men $(11,16)$, whereas others have shown otherwise $(7,14)$. Women tend to accumulate more subcutaneous fat, whereas men accumulate more visceral fat $(20)$; this could justify a more robust association in males. However, in patients diagnosed with metabolic syndrome, sex may not play a key role in other factors. The current study found that women had a greater prevalence of hypertension and hyperglycemia, both of which are metabolic risk factors. Consequently, when analyzing the association between neck circumference and abdominal circumference after controlling for these parameters, women showed a greater decrease in the $\beta$ coefficient than men.

\section{Relevance to clinical practice and recommendations}

Abdominal circumference is an anthropometric parameter traditionally used and recommended by international metabolic syndrome guidelines. However, certain disadvantages have been noted in its clinical use in patients at a risk of cardiovascular disease. For instance, a meta-analysis in older adults reported a $\mathrm{J}$ curve in the association between abdominal circumference and cardiovascular mortality, decreasing the reliability of this parameter (21). Conversely, neck circumference is an anthropometric parameter, which unlike abdominal circumference and BMI, does not have a measurement bias due to clothing and is simpler to measure. One study reported that a neck circumference of $\geq 38.5 \mathrm{~cm}$ had greater sensitivity for predicting metabolic syndrome, hyperglycemia, hypertension, hypertriglyceridemia, and low HDL cholesterol than an abdominal circumference of $\geq 90 \mathrm{~cm}$ in men and women (22). Therefore, clinicians should consider anthropometric and laboratory evaluations (fasting glucose and lipid profile) in patients with a high neck circumference value. Moreover, neck circumference assessment should be included in metabolic syndrome guidelines. Nonetheless, follow-up studies are warranted to continue identifying more robust methods of predicting cardiovascular events or mortality.

\section{Limitations}

Our study should be interpreted considering the following limitations. First, the study design did not allow us to establish a timeframe for the measurement of neck circumference along with abdominal circumference and BMI. Berkson's bias may exist by including only patients with access to the hospital, which would limit the extrapolation of results to other populations. Given that the patients studied were recruited from a community in the north of Peru, our findings may not be representative of all Peruvians with metabolic syndrome considering that dietary habits and other environmental exposures vary across Peru. However, despite these limitations, this study provides important evidence on the association of neck circumference with abdominal circumference and BMI in Peru and to our knowledge, is the first study of individuals with metabolic syndrome.

\section{Conclusions}

The current study found a significant positive linear correlation between neck circumference and abdominal circumference in both sexes in patients with metabolic syndrome from northern Peru, although such associations were greater in men than in women. Patients with elevated neck circumference should be evaluated for anthropometric and laboratory parameters, and neck circumference measurements should be implemented in the Peruvian metabolic syndrome guidelines. 


\section{Abbreviations}

BMI, body mass index

HDL, high-density lipoprotein

TG, triglycerides

\section{Declarations}

\section{Ethics approval and consent to participate}

This study was approved by the Institutional Review Board of the Hospital II-1 Chocope and the School of Human Medicine from the Universidad Nacional Pedro Ruiz Gallo.

\section{Consent for publication}

Not applicable

\section{Availability of data and materials}

The datasets used and/or analyzed during the current study are available from the corresponding author on reasonable request.

\section{Competing interests}

The authors declare that they have no competing interests.

\section{Funding}

Not applicable

\section{Authors' contributions}

VEF-R contributed to the conception, design, data collection, drafting, analysis, and interpretation of data. ED-G, DC-M, SZ-Ñ, and KS-S contributed to the data collection, data entry, drafting, analysis, and interpretation of data. MJV-G contributed to the conception, design, review, analysis, and interpretation of data. All authors read and approved the final manuscript.

\section{Acknowledgements}

The Fogarty International Center of the National Institutes of Health (NIH) training under Award Number D43TW001140 to VEFR and SZÑ.

\section{Authors' information}

Not applicable

\section{References}

1. Lipsy RJ. The National Cholesterol Education Program Adult Treatment Panel III guidelines. Journal of managed care pharmacy : JMCP. 2003;9(1 Suppl):2-5.

2. Saklayen MG. The Global Epidemic of the Metabolic Syndrome. Current hypertension reports. 2018;20(2):12.

3. McCracken E, Monaghan M, Sreenivasan S. Pathophysiology of the metabolic syndrome. Clinics in dermatology. 2018;36(1):14-20.

4. Rochlani Y, Pothineni NV, Kovelamudi S, Mehta JL. Metabolic syndrome: pathophysiology, management, and modulation by natural compounds. Therapeutic advances in cardiovascular disease. 2017;11(8):215-25.

5. Obeidat AA, Ahmad MN, Haddad FH, Azzeh FS. Evaluation of several anthropometric indices of obesity as predictors of metabolic syndrome in jordanian adults. Nutricion hospitalaria. 2015;32(2):667-77.

6. Wang H, Liu A, Zhao T, Gong X, Pang T, Zhou Y, et al. Comparison of anthropometric indices for predicting the risk of metabolic syndrome and its components in Chinese adults: a prospective, longitudinal study. BMJ open. 2017;7(9):e016062.

7. Özkaya I, Tunçkale A. Neck Circumference Positively Related with Central Obesity and Overweight in Turkish University Students: A Preliminary Study. Central European journal of public health. 2016;24(2):91-4.

8. Dai Y, Wan X, Li X, Jin E, Li X. Neck circumference and future cardiovascular events in a high-risk population-A prospective cohort study. Lipids in health and disease. 2016;15:46. 
9. Wang Y, Rimm EB, Stampfer MJ, Willett WC, Hu FB. Comparison of abdominal adiposity and overall obesity in predicting risk of type 2 diabetes among men. The American journal of clinical nutrition. 2005;81(3):555-63.

10. Assyov Y, Gateva A, Tsakova A, Kamenov Z. A comparison of the clinical usefulness of neck circumference and waist circumference in individuals with severe obesity. Endocrine research. 2017;42(1):6-14.

11. Saka M, Türker P, Ercan A, Kiziltan G, Baş M. Is neck circumference measurement an indicator for abdominal obesity? A pilot study on Turkish Adults. African health sciences. 2014;14(3):570-5.

12. Manual PanamSTEPS Sección 4: Guía para las mediciones físicas (Step 2). Organización Mundial de la Salud, Washington. 2017. https://www.who.int/ncds/surveillance/steps/Parte3_Seccion4.pdf. Accesed May 2020.

13. Lohman T, Roche A, Martorell R. Anthropometric Standardization Reference Manual. 1st ed. Champaign, Illinois: Human Kinetic Books; 1988.

14. Qureshi NK, Hossain T, Hassan MI, Akter N, Rahman MM, Sultana MM, et al. Neck Circumference as a Marker of Overweight and Obesity and Cutoff Values for Bangladeshi Adults. Indian journal of endocrinology and metabolism. 2017;21(6):803-8.

15. Hillier TA, Fagot-Campagna A, Eschwège E, Vol S, Cailleau M, Balkau B. Weight change and changes in the metabolic syndrome as the French population moves towards overweight: the D.E.S.I.R. cohort. International journal of epidemiology. 2006;35(1):190-6.

16. Anothaisintawee T, Sansanayudh N, Thamakaison S, Lertrattananon D, Thakkinstian A. Neck Circumference as an Anthropometric Indicator of Central Obesity in Patients with Prediabetes: A Cross-Sectional Study. BioMed research international. 2019;2019:4808541.

17. Ozkaya I, Yardimci B, Tunckale A. Appropriate neck circumference cut-off points for metabolic syndrome in Turkish patients with type 2 diabetes. Endocrinologia, diabetes y nutricion. 2017;64(10):517-23.

18. Fantin F, Comellato G, Rossi AP, Grison E, Zoico E, Mazzali G, et al. Relationship between neck circumference, insulin resistance and arterial stiffness in overweight and obese subjects. European journal of preventive cardiology. 2017;24(14):1532-40.

19. Ataie-Jafari A, Namazi N, Djalalinia S, Chaghamirzayi P, Abdar ME, Zadehe SS, et al. Neck circumference and its association with cardiometabolic risk factors: a systematic review and meta-analysis. Diabetology \& metabolic syndrome. 2018;10:72.

20. Fuente-Martín E, Argente-Arizón P, Ros P, Argente J, Chowen JA. Sex differences in adipose tissue: It is not only a question of quantity and distribution. Adipocyte. 2013;2(3):128-34.

21. de Hollander EL, Bemelmans WJ, Boshuizen HC, Friedrich N, Wallaschofski H, Guallar-Castillón P, et al. The association between waist circumference and risk of mortality considering body mass index in 65- to 74-year-olds: a meta-analysis of 29 cohorts involving more than 58 000 elderly persons. International journal of epidemiology. 2012;41(3):805-17.

22. Luo Y, Ma X, Shen Y, Xu Y, Xiong Q, Zhang X, et al. Neck circumference as an effective measure for identifying cardio-metabolic syndrome: a comparison with waist circumference. Endocrine. 2017;55(3):822-30.

\section{Figures}

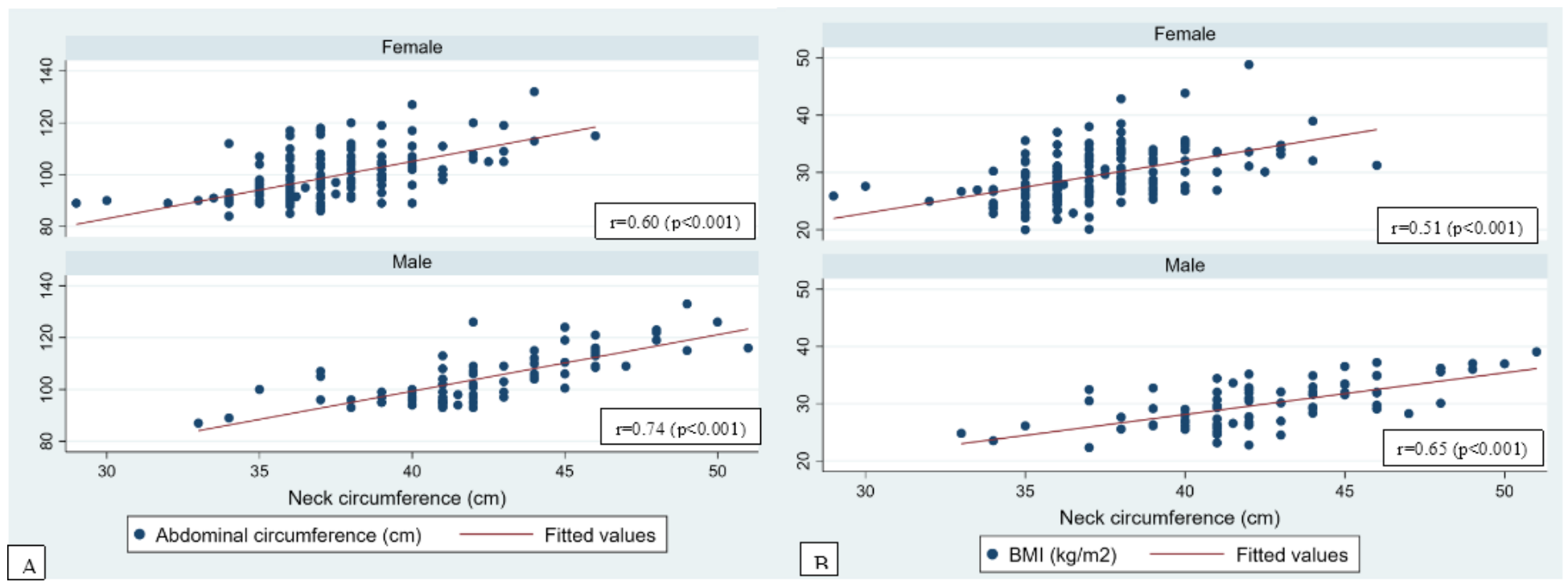

Figure 1

Correlation between neck circumference with abdominal perimeter and BMI by sex. A: Correlation between neck circumference and abdominal circumference. B: Correlation between neck circumference and body mass index (BMI). R: Pearson's correlation. BMI: Body Mass Index. 